\title{
Treatment of Lyme Arthritis
}

Infection with the tick-borne spirochete Borrelia burgdorferi leads to an estimated 300,000 new cases annually of Lyme disease in the United States. The northeastern United States is the most affected region, but the infection is also found in mid-Atlantic states, the upper Midwest, and in California ${ }^{1}$, and it now extends into Canada ${ }^{2}$. Lyme borreliosis in also endemic in parts of Europe and Asia ${ }^{1}$. In untreated patients, the infection generally occurs in stages, with different manifestations at each stage ${ }^{3}$. The disease usually begins with an expanding skin lesion, erythema migrans, accompanied by flu-like symptoms. Weeks later, untreated patients may have neurologic involvement, characterized by lymphocytic meningitis, cranial neuropathy, or radiculoneuropathy, or they may develop carditis, frequently manifested as atrioventricular nodal block. These manifestations of the disease can usually be treated successfully with appropriate antibiotic therapy for 2-4 weeks ${ }^{4}$.

In North America, arthritis is the most common late manifestation of Lyme disease ${ }^{5}$. Lyme arthritis (LA) typically begins months after the initial tick exposure, and without antibiotic treatment, it often causes intermittent or persistent, monoarticular or oligoarticular arthritis, usually in 1 or 2 joints at a time, especially the knees, over a period of several years. Tendons, ligaments, or bursae may also be affected. Because early Lyme disease is usually recognized and treated effectively with antibiotic therapy, LA is typically seen now only in patients with minimal or no symptoms of early infection. Such patients present with arthritis at any time of the year, not only in the summer. Both children and adults are affected. Patients with LA generally have the highest IgG antibody responses seen in Lyme disease, as determined by ELISA, with expansion of the response to many spirochetal proteins, as shown by Western blotting.

Similar to the experience with early Lyme disease, LA can often be treated successfully with 30 days of oral antibiotic therapy. In an early randomized study of 40 patients with LA, manifested as knee swelling and pain, $\sim 90 \%$ had resolution of the arthritis in 1-3 months after a 30-day course of oral doxycycline or amoxicillin, without further treatment ${ }^{6}$. However, it later became apparent that a subgroup of patients with LA had minimal or no improvement even with multiple courses of oral antibiotic therapy, but achieved resolution of arthritis during or within weeks of a 28-day course of intravenous (IV) antibiotic therapy ${ }^{7}$.

In contrast, despite spirochetal killing with oral and IV antibiotics, another subgroup of patients developed a marked inflammatory, proliferative synovitis lasting months to several years after antibiotic treatment ${ }^{7,8}$, and it did not respond to further antibiotic therapy ${ }^{6}$. Accordingly, we originally called this complication antibiotic-refractory LA. However, it is now clear that this complication is not caused by antibiotic resistance or failure of spirochetal killing 9 . Rather, following resolution of B. burgdorferi infection, appropriate tissue repair appears to be stalled by excessive interferon- $\gamma$-mediated inflammation, preventing wound healing and return of tissue homeostasis ${ }^{8}$. This results in a synovial lesion typical of that found in other forms of chronic inflammatory arthritis, including rheumatoid arthritis. The lesion is characterized by vascular damage, infiltration of mononuclear cells, proliferation of synovial fibroblasts, marked fibrosis, and autoimmune processes lasting for months to several years, which we now call postinfectious $\mathrm{LA}^{8}$.

This range of outcomes leads to a conundrum. Do LA patients with little or no apparent response to oral antibiotic therapy still have active $B$. burgdorferi infection requiring IV antibiotic therapy, do they have postinfectious LA requiring therapy with disease-modifying antirheumatic drugs (DMARD), or do they have another form of chronic inflammatory arthritis? Either IV antibiotics or DMARD, given inappropriately, might be harmful.

Based on clinical experience, we have developed an algorithm for the treatment of $\mathrm{LA}^{7,10}$. We begin with oral antibiotic therapy for 1 month. If the patient has a substantial but incomplete response, we typically treat for a second month with oral antibiotics. However, if there is minimal or

\section{See Lyme arthritis second-line treatment, page 952}


no response, we treat with IV antibiotic therapy for 28 days. Most such patients improve considerably with IV therapy, and in some, the arthritis resolves by the end of this therapy or in the following weeks. In others, the arthritis changes to a marked proliferative synovitis, which may even worsen in the postantibiotic period. We treat these patients with DMARD such as hydroxychloroquine, methotrexate, or tumor necrosis factor inhibitors, the standard of care for other forms of chronic inflammatory arthritis. We have not seen re-emergence of infection in these patients. Because only 1 knee is usually affected, arthroscopic synovectomy is also an option.

The role of intraarticular steroid injections in this algorithm is unclear. As shown in a non-human primate model, glucocorticoids are permissive to the spirochete and increase the spirochetal burden ${ }^{11}$. In one treatment study of human LA, their use prior to antibiotic therapy was associated with the failure of antibiotic therapy ${ }^{12}$, whereas in another study, it was not ${ }^{6}$. In children with septic arthritis, short courses of dexamethasone with IV antibiotics have been reported to reduce the number of days of hospitalization and antibiotic treatment ${ }^{13}$. Still, in patients with LA, our practice has been to limit the use of intraarticular steroids to the postinfectious period. In a patient with a lingering joint effusion after IV antibiotic therapy, intraarticular steroids or nonsteroidal antiinflammatory drugs perhaps lead to faster resolution of arthritis. At the opposite end of the spectrum, in patients with severe postinfectious LA, an intraarticular steroid injection may serve as a "bridge" when starting DMARD, particularly in a patient with marked joint pain.

In a recent study by Horton, et al reported in this issue of The Journal ${ }^{14}$, a retrospective analysis was done of children with LA who were treated by pediatric rheumatologists in 3 pediatric hospitals in New Jersey and Pennsylvania. In these referral centers, an incomplete response to an initial 1-month course of oral antibiotic therapy was not unusual. Of 383 patients with LA, 112 (29\%) were given a second course of treatment, and 43 of 112 (38\%) developed antibiotic-refractory LA (ARLA), defined in this study as persistent active LA for $>2$ months after completing $>8$ weeks of oral antibiotics or $>2$ weeks of IV antibiotics, or persistent arthritis for $>3$ months after a 1-month course of oral antibiotics.

Risk factors for ARLA included age $>10$ years, prolonged duration of arthritis prior to treatment, and worsening of arthritis after starting antibiotics ${ }^{15}$. The greater frequency of ARLA in older children may be explained by the rising incidence of autoimmune disease during adolescence compared with prepubertal children ${ }^{16}$. A longer duration of arthritis prior to treatment in patients with ARLA may allow a longer duration for development of an excessive, dysregulated immune response. Finally, worsening of arthritis during treatment may also provide a clinical clue to the development of such an immune response.

The major finding was that ARLA developed in only 3 of
18 patients (17\%) who were given an intraarticular steroid injection as second-line therapy, in 13 cases accompanied by a second course of oral antibiotics, compared with 28 of 63 patients (44\%) who were given a second course of oral antibiotics alone $(p=0.052 \text {, Fisher's exact test, 2-tailed })^{14}$. The intriguing concept is that it may be possible to reduce the risk of excessive synovial inflammation by giving intraarticular steroids while treating, in most cases, with a second course of antibiotic therapy. This may reduce the risk of developing the "full-blown" dysregulated inflammatory response associated with postinfectious LA. This is a provocative finding. However, it should be emphasized that this was not a randomized study, and the number of patients given intraarticular glucocorticoids alone was small.

There remain other unanswered questions. First, was the infection treated adequately with the first course of oral antibiotics or did some of the children still have residual infection when they were given the second course of oral antibiotics? PCR testing does not allow this distinction, because $B$. burgdorferi DNA may persist for weeks or longer after spirochetal killing, and conversely, active infection may still be present despite a negative PCR result. Because it is difficult to rule out residual infection if joint swelling is still present after an initial course of antibiotics, it may make sense to give antibiotics if the physician is treating with intraarticular steroids as secondary therapy.

Second, what is the role of IV antibiotics for secondary therapy? Here, they were reserved for children who had more severe or worsening arthritis during initial oral therapy, and exploratory analyses suggested that adolescents with this disease course were more likely to respond to IV antibiotics ${ }^{14}$. Our experience also suggests that even multiple courses of oral antibiotic therapy may not always result in spirochetal elimination from joints, and IV antibiotic therapy may be required for successful treatment of the infection. One hypothesis to explain this finding is that spirochetes may sometimes survive in tendons or ligaments in and around joints, a relatively avascular niche, from which they can periodically seed synovial tissue ${ }^{17,18}$. In such patients, IV antibiotic therapy, which results in higher blood levels and better tissue penetration than oral antibiotics, may be necessary for spirochetal killing.

Third, can this experience in children be generalized to adults? Although LA appears to be milder in young children ${ }^{19}$, adolescent LA seems to be similar to the disease in adults. Fourth, can the results in New Jersey and Pennsylvania be generalized to other geographic regions? In Europe, where the infection is caused primarily by $B$. afzelii or $B$. garinii, arthritis is less common and is usually less severe than in the northeastern United States. Moreover, the mix of Borrelia strains and the frequency and severity of arthritis vary even within the United States. For example, based on isolates of $B$. burgdorferi from erythema migrans skin lesions, $30 \%$ of the isolates from the Lyme, Connecticut,

Personal non-commercial use only. The Journal of Rheumatology Copyright $\odot$ 2019. All rights reserved. 
area were highly inflammatory OspC type A strains, compared with $16 \%$ from Westchester County, New York, and only $6 \%$ from Wisconsin ${ }^{20}$. Infection with OspC type A (RST1) strains is associated with more severe early disease and an increased frequency of postinfectious $\mathrm{LA}^{21,22}$. Thus, the frequency of severe outcomes requiring more aggressive treatment may be more common in certain geographic regions.

Importantly, the questions surrounding the secondary treatment for LA can be answered definitively only by systematic, randomized studies. As a part of such studies, it may be possible to develop biomarkers, such as ultrasound imaging $^{18}$ or determination of certain microRNA ${ }^{23}$, cytokines $^{21}$, or autoantibodies ${ }^{24,25}$, to help delineate patients with residual infection versus those with postinfectious LA. Such knowledge is needed to improve outcomes in children and adults with this potentially severe form of infection-induced inflammatory arthritis.

\section{ALLEN C.STEERE, MD,}

Center for Immunology and Inflammatory Diseases, Division of Rheumatology, Allergy, and Immunology, Massachusetts General Hospital,

Harvard Medical School,

Boston, Massachusetts, USA.

Supported by the US National Institutes of Health (National Institute of Allergy and Infectious Diseases grants R01-AI-101175 and

R01-AI-144365), the Mathers Foundation, the Eshe Fund, and

Massachusetts General Hospital (Lyme Disease and Arthritis Fund).

Address correspondence to Dr. A.C. Steere, Massachusetts General

Hospital, 55 Fruit St., Boston, Massachusetts 02114, USA.

E-mail: asteere@partners.org

\section{REFERENCES}

1. Mead PS. Epidemiology of Lyme disease. Infect Dis Clin North Am 2015;29:187-210.

2. Ogden NH, Lindsay LR, Morshed M, Sockett PN, Artsob H. The rising challenge of Lyme borreliosis in Canada. Can Commun Dis Rep 2008;34:1-19.

3. Steere AC. Lyme disease. N Engl J Med 1989;321:586-96.

4. Wormser GP, Dattwyler RJ, Shapiro ED, Halperin JJ, Steere AC, Klempner MS, et al. The clinical assessment, treatment, and prevention of Lyme disease, human granulocytic anaplasmosis, and babesiosis: clinical practice guidelines by the Infectious Diseases Society of America. Clin Infect Dis 2006;43:1089-134.

5. Steere AC, Schoen RT, Taylor E. The clinical evolution of Lyme arthritis. Ann Intern Med 1987;107:725-31.

6. Steere AC, Levin RE, Molloy PJ, Kalish RA, Abraham JH 3rd, Liu NY, et al. Treatment of Lyme arthritis. Arthritis Rheum 1994;37:878-88.

7. Steere AC, Angelis SM. Therapy for Lyme arthritis; strategies for the treatment of antibiotic-refractory arthritis. Arthritis Rheum 2006;54:3079-85.

8. Lochhead RB, Arvikar SL, Aversa JM, Sadreyev RI, Strle K, Steere AC. Robust interferon signature and suppressed tissue repair gene expression in synovial tissue from patients with post-infectious, Borrelia burgdorferi-induced Lyme arthritis. Cell Microbiol 2018:e12954.
9. Li X, McHugh G, Damle N, Sikand VK, Glickstein L, Steere AC. Burden and viability of Borrelia burgdorferi in skin or joints of patients with erythema migrans or Lyme arthritis. Arthritis Rheum 2011;63:2238-47.

10. Arvikar SL, Steere AC. Diagnosis and treatment of Lyme arthritis. Infect Dis Clin North Am 2015;29:269-80.

11. Pachner AR, Delaney E, O'Neill T, Major E. Inoculation of nonhuman primates with the N40 strain of Borrelia burgdorferi leads to a model of Lyme neuroborreliosis faithful to the human disease. Neurology 1995;45:165-72.

12. Dattwyler RJ, Halperin JJ, Volkman DJ, Luft BJ. Treatment of late Lyme borreliosis - randomized comparison of ceftriaxone and penicillin. Lancet 1988;1:1191-4.

13. Qin YF, Li ZJ, Li H. Corticosteroids as adjunctive therapy with antibiotics in the treatment of children with septic arthritis: a meta-analysis. Drug Des Devel Ther 2018;12:2277-84.

14. Horton DB, Taxter AJ, Davidow AL, Groh B, Sherry DD, Rose CD Intraarticular glucocorticoid injection as second-line treatment for Lyme arthritis in children. J Rheumatol 2019;46:952-9.

15. Horton DB, Taxter AJ, Davidow AL, Groh B, Sherry DD, Rose CD Pediatric antibiotic-refractory Lyme arthritis: a multicenter case-control study. J Rheumatol 2019;46:943-51.

16. Nigrovic PA, Raychaudhuri S, Thompson SD. Review: genetics and the classification of arthritis in adults and children. Arthritis Rheumatol 2018;70:7-17.

17. Bockenstedt LK, Wormser GP. Review: unraveling Lyme disease. Arthritis Rheumatol 2014;66:2313-23.

18. Arvikar S, Kohler M, Oza A, Steere AC. Ultrasonographic examinations show highly prevalent abnormalities of hamstring tendons in Lyme arthritis patients [abstract]. Arthritis Rheumatol 2018;70 Suppl 10:950.

19. Szer IS, Taylor E, Steere AC. The long-term course of children with Lyme arthritis. N Engl J Med 1991;325:159-63.

20. Hanincova K, Mukherjee P, Ogden NH, Margos G, Wormser GP, Reed KD, et al. Multilocus sequence typing of Borrelia burgdorferi suggests existence of lineages with differential pathogenic properties in humans. PLoS One 2013;8:e73066.

21. Strle K, Shin JJ, Glickstein LJ, Steere AC. Association of a toll-like receptor 1 polymorphism with heightened Th1 inflammatory responses and antibiotic-refractory Lyme arthritis. Arthritis Rheum 2012;64:1497-507.

22. Jones KL, McHugh GA, Glickstein LJ, Steere AC. Analysis of Borrelia burgdorferi genotypes in patients with Lyme arthritis: high frequency of ribosomal RNA intergenic spacer type 1 strains in antibiotic-refractory arthritis. Arthritis Rheum 2009;60:2174-82.

23. Lochhead RB, Strle K, Kim ND, Kohler MJ, Arvikar SL, Aversa $\mathrm{JM}$, et al. MicroRNA expression shows inflammatory dysregulation and tumor-like proliferative responses in joints of patients with post-infectious Lyme arthritis. Arthritis Rheumatol 2017; 69:1100-10.

24. Drouin EE, Seward RJ, Strle K, McHugh G, Katchar K, Londono D, et al. A novel human autoantigen, endothelial cell growth factor, is a target of $\mathrm{T}$ and $\mathrm{B}$ cell responses in patients with Lyme disease. Arthritis Rheum 2013;65:186-96.

25. Crowley JT, Strle K, Drouin EE, Pianta A, Arvikar SL, Wang Q, et al. Matrix metalloproteinase-10 is a target of $\mathrm{T}$ and $\mathrm{B}$ cell responses that correlate with synovial pathology in patients with antibiotic-refractory Lyme arthritis. J Autoimmun 2016;69:24-37.

J Rheumatol 2019;46:871-3; doi:10.3899/jrheum.190320

Personal non-commercial use only. The Journal of Rheumatology Copyright (C) 2019. All rights reserved. 